\title{
RELIABILITY-BASED DESIGN PROCEDURE FOR FATIGUE CRACKING IN ASPHALT PAVEMENTS
}

\author{
Yared H. Dinegdae, Corresponding Author \\ PhD Candidate \\ KTH Royal Institute of Technology \\ Dept. of Civil and Architectural Engineering \\ Brinellvägen 23, SE-10044 \\ Stockholm, Sweden \\ Phone (46)73664-0899, Fax (46)8790-7928 \\ dinegdae@kth.se
}

\author{
Björn Birgisson \\ Professor \\ Aston University \\ School of Engineering and Applied sciences \\ Aston Triangle, Birmingham B4 7ET, UK \\ Phone (44)7825 125908 \\ bjorn.birgisson@aston.ac.uk
}

Word count: 4,787 words text +8 tables/figures $x 250$ words (each) $=6,787$ words

TRR Paper number: 16-2037

Submission Date: March 03, 2016 


\begin{abstract}
The need to account for design inputs variabilities effect on predicted performance has led many design procedures to address the issue of reliability for pavement applications. The Florida cracking model utilizes an empirically derived reliability for fatigue cracking design of asphalt pavements. A reliability approach, which is based on probabilistic uncertainty quantification, is necessary in order to account properly and effectively for the contribution of the variability in each parameter to the overall variance. This paper presents a load and resistance factor design (LRFD) procedure for the Florida cracking model. By delivering designs of uniform reliability, LRFD provides the basis for developing quality control and quality assurance standards. A first order reliability method (FORM) which incorporates central composite design (CCD) based surrogate model is employed to compute the reliability and formulate the partial safety factors. The reliability calibration was achieved based on field pavement sections that have a wide range in design inputs and target reliability. Illustrative designs based on the developed LRFD procedure has shown the effectiveness of the partial safety factors, and thus giving further confirmation to the credibility of the employed reliability analysis methodology.
\end{abstract}

Keywords: Reliability, fatigue cracking, LRFD, FORM, CCD, pavement design 


\section{INTRODUCTION}

Load induced top-down fatigue cracking (i.e., cracking that initiates at the surface of asphalt concrete (AC) layer and propagates downward) has been observed in many parts of the world (e.g., 1-4). It is widely accepted that top-down cracking results from a critical combination of load, thermal and aging effects. A multi-year research at the University of Florida has led to the development of a new hot mix asphalt fracture mechanics (HMA-FM) framework. HMA-FM is based on visco-elastic principle and predicts the initiation and propagation of top-down cracking (e.g., 5, 6). Based on the performance evaluation of field pavement sections, a parameter termed energy ratio (ER) which relates well with the observed performance in the field was identified and introduced into HMA-FM (7). Utilizing ER as a design criterion, a mechanistic empirical (M-E) pavement design model for top-down fatigue cracking was developed. The model was calibrated and validated on a number of field pavement sections from the State of Florida and has been found to be successful in distinguishing pavement sections which exhibited cracking from those that did not. The energy ratio method has recognized the importance of accounting for the effects of uncertainty in design inputs on predicted performance, and has therefore incorporated an empirically derived reliability concept. These reliability factors were developed by fitting computed ER values of a single section with respective target reliabilities without accounting directly for the effects of design inputs variabilities on performance (8). A reliability which is not based on probabilistic method of uncertainty propagation might not give designs of uniform target reliability thus, limiting the intended benefits of the design procedure.

A reliability analysis which is based on a probabilistic method of uncertainty propagation enables the design procedure to account for design input uncertainty effects on predicted performance. The first order reliability method (FORM), which is one of a number of reliability analysis techniques, has been employed in the structural reliability community for quantifying the reliability of many practical engineering design problems (e.g., 9, 10, 11). Moreover, FORM can be used to develop reliability-based codified design procedures such as factor of safety (FOS) and load and resistance factor design (LRFD). LRFD is based on the limit state design concept and considers the uncertainty and influence of each design parameter through a set of partial safety factors. These partial safety factors are derived from reliability analysis and reflect the degree of influence and associated variability of design parameters and required safety level. The LRFD method has already been adopted by many structural design specifications (e.g., 12, $13,14)$ and there is an ongoing research regarding its application and implementation for pavement analysis and design $(15,16,17)$. Adopting a LRFD procedure for pavement analysis and design would provide a significant benefit as it mitigates some of the drawbacks and limitations that exist in the current procedures. By providing designs of uniform reliability, LRFD provides the basis on which quality control and quality assurance can be performed.

This paper presents a LRFD framework for the Florida cracking model. A reliability analysis methodology that utilizes central composite design-based (CCD) response surface approach and first order reliability method was used to compute the reliability and formulate the partial safety factors. Another key objective of this paper was to evaluate the effectiveness of the CCD based response surface for its applicability as a surrogate for pavement reliability computations. Moreover, an investigation was undertaken to establish the inherent variability of the design inputs which were found to have significant influence on predicted cracking performance. A number of field pavement sections that have a wide range in design inputs and target reliability were used for developing the LRFD framework. The new LRFD procedure is 
capable of designing pavement sections of various target reliabilities and can be used to supplement existing M-E pavement design procedures.

\section{FLORIDA CRACKING MODEL}

The Florida cracking model (ER method) is a Level 3 M-E pavement design tool for top-down fatigue cracking. This model was developed on the basis of HMA-FM and can be used to optimize pavement thickness for new, existing and rehabilitated asphalt pavements. HMA-FM was developed on the basis that there exists an energy fracture threshold in asphalt mixtures which is independent of loading mode and loading history. This energy threshold is called dissipated creep strain energy limit $\left(\mathrm{DCSE}_{\mathrm{f}}\right)$ and governs the resistance of the mixtures against cracking. Damage due to traffic applications accumulates in the form of dissipated creep strain energy $\left(\mathrm{DCSE}_{\min }\right)$ and once this damage exceeds the limit or threshold energy a crack initiates or if it already exists it propagates $(5,6)$. Utilizing these energy based parameters, the Florida cracking model determines the initiation and propagation of cracks in asphalt mixtures for any loading condition.

The ER parameter, which defines a relation between DCSE $_{\mathrm{f}}$ and DCSE $_{\min }$, was incorporated into the HMA-FM model after an extensive cracking performance study of 22 field pavement sections. Evaluation of the cracking performance of these sections based on the ER method indicated that this parameter distinguished successfully the cracked sections from those that did not crack. The ER is a dimensionless parameter, and according to Roque et al. (7) it is defined as the limit dissipated creep strain energy divided by the minimum dissipated creep strain energy:

$$
E R=\frac{D C S E_{f}}{D C S E_{\text {min }}}
$$

Finding a predictive equation for $\mathrm{DCSE}_{\mathrm{f}}$, which has been correlated to mixtures cracking resistance, was found to be extremely difficult (e.g. 5, 6, 7). Therefore, on the basis of the relation between $\mathrm{DCSE}_{\mathrm{f}}$ and creep rate in tension, the following predictive model that considers the creep rate at time $\mathrm{t}=1000$ s was proposed:

$$
D C S E_{f}=c_{f} S_{t} \frac{m D_{1}}{10^{3(1-m)}}
$$

where $c_{f}$ is a function of binder viscosity and equals to $6.9^{*} 10^{7} . \mathrm{S}_{\mathrm{t}}, \mathrm{m}$ and $\mathrm{D}_{1}$ are tensile strength and creep compliance parameters of the asphalt mixture respectively. A model which is a function of creep compliance parameters, tensile strength and maximum tensile stress is developed for the $\mathrm{DCSE}_{\min }$ estimation:

$$
D C S E_{\min }=\frac{m^{2.98} D_{1}}{f\left(S_{t}, \sigma_{\max }\right)}
$$

The maximum tensile stress at the bottom of the AC layer is estimated by employing multilayer linear elastic analysis and it is related to the tensile strength by the following equation:

$$
f\left(S_{t}, \sigma_{\max }\right)=\frac{6.36-S t}{33.44 \sigma_{\max }^{3.1}}+2.46 \cdot 10^{-8}
$$


The design of pavement sections with the ER method is performed on the premise that a crack will form after a certain number of years. As a Level $3 \mathrm{M}-\mathrm{E}$ design tool, the Florida cracking model incorporates material models to estimate the changes in material properties such as dynamic modulus, tensile strength and creep compliance parameters. The final design cross section is determined through optimization that accounts for the structure and asphalt mixture for average conditions, and which satisfies the design criterion i.e. ER $\approx 1$.

The Florida cracking model recognized the need to account for traffic and reliability effects on design thickness, and adjusted the minimum required ER values accordingly. Wang et al. $(8)$ developed optimum energy ratio $\left(\mathrm{ER}_{\mathrm{opt}}\right)$ values based on empirical reliability calibration for various traffic levels and target reliabilities. As these optimum ER values were developed in conjunction with an existing design procedure, this enabled the target reliabilities to incorporate the risk level implied in the existing procedure. This also minimizes the design deviation that could happen between the ER and existing design methods. Further development was undertaken to decouple traffic and reliability effects from $E_{\text {opt }}$ so as to obtain an optimum equation that could be used to estimate $\mathrm{ER}_{\text {opt }}$ values for given reliability and traffic levels. $\mathrm{ER}_{\text {opt }}$ as a function of traffic level $(\gamma)$ and reliability $(\varphi)$ can be determined as follows:

$$
E R_{o p t}=\frac{\gamma}{\varphi}
$$

\section{RELIABILITY METHODS}

Pavement design process is stochastic in nature. Input inherent variability, model bias and statistical characterization are the main sources of uncertainties in pavement design (18). The combined effect of the variances associated with these uncertainties has a profound influence on pavement performance (e.g., 19, 20, 21). The need for a sound reliability analysis and its applicability for pavement design has been recognized and addressed as early as the 1970s (e.g., 19, 22, 23). Numerical based analyses which employ Monte Carlo simulation have also greatly advanced the understanding and applicability of reliability principles to pavement design (24, 25). There are also papers which focus on the applicability of analytical based reliability analysis tools such as first order reliability method (FORM) for pavement reliability evaluation (e.g., 15,16,26).

Pavement design reliability can be defined as the probability that the traffic load capacity of the pavement exceeds the cumulative traffic load applications during the design period. Based on distress, the same reliability can be defined as the probability that the amount of distress during the design period does not exceed a specified critical level $(27,28)$. The performance equation (PE) for the Florida cracking model can be defined as follows:

$$
P E=D C S E_{f}-T F \cdot D C S E_{\text {min }}
$$

where TF is traffic factor that equals 1 . TF is introduced into the Florida Cracking model to account for the effect of traffic variability on predicted energy ratio. Establishing the statistical parameters of the performance equation is not an easy task as it is the outcome of many independent random variables. Based on their degree of influence, parameters such as layer moduli, layer thicknesses, traffic characterization inputs and environmental factors should be identified and statistically characterized. The probability of failure $\left(p_{f}\right)$ in the case when the variability of independent parameters is defined by a full probability density function (pdf) can be computed as follows: 


$$
P_{f}=p\{g(x) \leq 0\}=\int_{g(x) \leq 0} f_{x}(x) d x
$$

where $f_{x}(x)$ is the joint probability density function of the independent variables $\left(\mathrm{x}_{1}, \mathrm{x}_{2}, \ldots . \mathrm{x}_{\mathrm{n}}\right)$ and $g(x)=0$ indicates the boundary between the safe and failure regions. In equation 7 , the probability of failure is obtained by integrating the joint probability density function over the failure region. Once the probability of failure is determined, the reliability $(R)$ can be computed as follows:

$$
R=p\{g(x) \geq 0\}=1-P_{f}
$$

Finding an exact solution to the integration problem in Equation 7 is possible only for special cases, and numerical integration will become impractical when the number of variables exceeds 2 or 3 . Nevertheless, there are several methods which can be employed to obtain an approximation solution to this integral. The First order reliability method (FORM) is one of these methods and has been used extensively for structural reliability problems. FORM obtains an approximation solution to the reliability problem by linearizing the limit state equation at the most likely failure point in the standard normal space $(11,29)$. The distance from the origin to this point is termed reliability index $(\beta)$ and the probability of failure is calculated as follows:

$$
P_{f}=\phi(-\beta)
$$

where $\phi(\cdot)$ is the standard normal distribution function. There are multiple methods which utilize the FORM principle and their application depends on the complexity of the reliability problem. The algorithm suggested by Rackwitz and Fiessler (11) is well suited for problems that involve high nonlinearity and non-normal variables.

The application of analytical-based reliability analysis tools requires the performance function to be expressed by an explicit closed-form function of the design input variables. However, most engineering applications incorporate finite element method or linear elastic analysis to compute the response of structures which further complicates the reliability analysis. One approach to establish an explicit mathematical expression to an implicit performance function is through a response surface approach. Central Composite Design (CCD) based response surface methodology can be used to generate an efficient second degree polynomial surrogate model (30). CCD generates the performance function by employing regression analysis on trials points which are generated through first order $\left(2^{\mathrm{n}}\right)$, center and axial points interaction. For an output response $(y)$ and input variables $\left(\mathrm{x}_{1}, \mathrm{x}_{2}, \mathrm{x}_{3} \ldots\right)$ linear regression analysis generates with an error $(\varepsilon)$ the following equation:

$$
y=f\left(x_{1}, x_{2}, x_{3} \ldots \ldots\right)+\varepsilon
$$

\section{PAVEMENT SECTIONS}

Pavement sections that have a well-documented top-down fatigue cracking performance history as well as high quality laboratory and field data are required for the reliability calibration. Moreover, these sections should exhibit the design features and conditions that exist in practice and also encompass the expected range in the design inputs. For this purpose, 24 pavement sections that have a wide range in target reliabilities and design inputs from the state of Florida were used (e.g., 7, 31, 32). The target reliabilities of the sections were established by following the guidelines and recommendations specified in the Florida Department of Transportation 
(FDOT) pavement design guide (33). Developing a reliability-based calibration in conjunction with an existing design guide will insure proper design evolution and minimize design deviations. A summary of information regarding the source and associated inputs of the pavement sections selected for the reliability calibration is provided in Tables 1 and 2 .

Group 1: The following 14 pavement sections were part of the group used by Dinegdae et al. (31) for the development of a mechanics based top-down fatigue cracking design framework. A summary of information about these pavement section sis provided in Table 1.

TABLE 1 Summary of Information for Group One Pavement Sections

\begin{tabular}{lcccc}
\hline Section & County & $\begin{array}{c}\text { Traffic } / \text { year } \\
\left(\text { ESALs } 10^{3}\right)\end{array}$ & $\begin{array}{l}\text { Computed } \\
\text { ER }\end{array}$ & $\begin{array}{l}\text { Target } \\
\text { Reliability (\%) }\end{array}$ \\
\hline I75-1A & Charlotte & 573 & 1.21 & 95 \\
I75-1B & Charlotte & 558 & 1.20 & 95 \\
I75-3 & Lee & 674 & 1.21 & 95 \\
I75-2 & Lee & 576 & 3.55 & 95 \\
SR80-2 & Lee & 207 & 1.04 & 85 \\
US 19-2 & Taylor & 30 & 1.06 & 75 \\
I-75SB & Hamilton & 1,040 & 2.23 & 95 \\
I-75SB2 & Hamilton2 & 1,190 & 4.75 & 95 \\
I-10EB & Duval & 1,010 & 1.74 & 95 \\
US-301SB & Marion & 510 & 1.22 & 95 \\
SR 89 & SantaRosa & 30 & 1.32 & 75 \\
A1A & Dade & 411 & 4.53 & 90 \\
SR60 & Hillsborough & 312 & 1.24 & 90 \\
TPK-1 & St. Lucie & 27 & 2.21 & 75 \\
\hline
\end{tabular}

Group 2: Additional 10 pavement sections from Zou (32) and Roque et al. (7) are also used. A summary of information about these pavement sections is provided in Table 2.

TABLE 2 Summary of Information for Group Two Pavement Sections

\begin{tabular}{lcccc}
\hline Section & County & $\begin{array}{c}\text { Traffic } / \text { year } \\
\left(\text { ESALs } 10^{3}\right)\end{array}$ & $\begin{array}{l}\text { Computed } \\
\text { ER }\end{array}$ & $\begin{array}{l}\text { Target } \\
\text { Reliability (\%) }\end{array}$ \\
\hline I10MW-2 & Madison & 546 & 1.10 & 95 \\
I95DN & Duval & 1,192 & 8.89 & 95 \\
I95SJN & St. John & 1,192 & 2.12 & 95 \\
I10DE & Duval & 681 & 1.48 & 95 \\
I10DW & Duval & 681 & 1.14 & 95 \\
US301BN & Bradford & 558 & 3.13 & 95 \\
US301BS & Bradford & 558 & 1.04 & 95 \\
I10-8 & Suwannee & 392 & 1.69 & 90 \\
I10-9 & Suwannee & 392 & 2.09 & 90 \\
SR997 & Dade & 89 & 1.10 & 80 \\
\hline
\end{tabular}


The ER values reported in Table 1 and 2 are predicted performances at the $15^{\text {th }}$ year. A careful investigation of the performance history of field pavement sections in Florida has shown that a crack initiates on average at the $10^{\text {th }}$ year and pavements fail subsequently after about an additional 5 years of service life (34). Based on this finding, a design period of 15 years was selected for the reliability based Florida cracking model. Table 3 presents the performance history of some of the sections used for establishing this design period.

\section{TABLE 3 Pavement Sections Cracking Performance}

\begin{tabular}{lccc}
\hline Section & County & $\begin{array}{c}\text { Observed crack } \\
\text { initiation (year) }\end{array}$ & $\begin{array}{c}\text { Observed crack } \\
\text { failure (year) }\end{array}$ \\
\hline I-75SB & Hamilton & 9 & 14 \\
I-10EB & Duval & 13 & 20 \\
I-75SB2 & Hamilton & 10 & 15 \\
I75-3 & Lee & 11 & 13 \\
I75-2 & Lee & 12 & 20 \\
I75-1A & Charlotte & 10 & 13 \\
I75-1B & Charlotte & 11 & 16 \\
US-301SB & Marion & 11 & 13 \\
US19-2 & Taylor & 8 & 10 \\
SR89 & SantaRosa & 6 & 10 \\
A1A & Dade & 12 & 14 \\
SR60 & Hillsborough & 11 & 16 \\
SR80-2 & Lee & 15 & 18 \\
\hline \multicolumn{5}{r}{} & Average & 10.7 & 14.8 \\
\hline
\end{tabular}

\section{DESIGN INPUTS VARIABILITIES}

The Florida cracking model involves many design variables, and the statistical properties of these parameters are necessary for the reliability analysis. As it is uneconomical to model all the design inputs as random variables, a parametric study was performed to identify those parameters that have a significant influence on performance. A typical four layer pavement structure Lee SR80-2 was selected for this purpose. Design inputs such as AC thickness $\left(\mathrm{H}_{\mathrm{AC}}\right)$, $\mathrm{DCSE}_{\mathrm{f}}$, TF and base modulus $\left(\mathrm{E}_{\mathrm{B}}\right)$ have been shown to be the dominant in the parametric study. A literature review was conducted to establish the statistical properties of these parameters and those design inputs such as base thickness $\left(\mathrm{H}_{\mathrm{B}}\right)$, subbase modulus $\left(\mathrm{E}_{\mathrm{SB}}\right)$, and subbase thickness $\left(\mathrm{H}_{\mathrm{SB}}\right)$. A summary of the literature review and the variabilities which are adopted for this paper can be seen in Table 4. 
TABLE 4 Design Inputs Variabilities

\begin{tabular}{|c|c|c|c|}
\hline Parameter & $\begin{array}{l}\text { Literature Review } \\
\text { Variability }\end{array}$ & nce & This study \\
\hline \multirow{4}{*}{$\begin{array}{l}\text { Asphalt } \\
\text { thickness }\end{array}$} & Normal, COV (3\% - 12\%) & Timm et al. (25) & \multirow{4}{*}{$\begin{array}{l}\text { Normal, } \\
\text { COV }(10 \%)\end{array}$} \\
\hline & Normal, COV $(3 \%-12 \%)$ & Noureldin et al. (20) & \\
\hline & Normal, COV $(3 \%-25 \%)$ & Bush (35) & \\
\hline & Normal, COV (10\%) & Darter et al. (19) & \\
\hline \multirow{3}{*}{$\begin{array}{l}\text { Base } \\
\text { thickness }\end{array}$} & Normal, COV (10\% - 15\%) & Timm et al. (25) & \multirow{3}{*}{$\begin{array}{l}\text { Normal, } \\
\text { COV }(12 \%)\end{array}$} \\
\hline & Normal, COV $(5 \%-35 \%)$ & Bush (35) & \\
\hline & Normal, COV (10\%) & Darter et al. (19) & \\
\hline $\begin{array}{l}\text { Subbase } \\
\text { thickness }\end{array}$ & Normal, COV (10\% - 20\%) & Timm et al. (25) & $\begin{array}{c}\text { Normal, } \\
\text { COV }(15 \%)\end{array}$ \\
\hline \multirow{3}{*}{$\begin{array}{l}\text { Base } \\
\text { modulus }\end{array}$} & Log-normal, COV (15\% - 50\%) & Timm et al. (25) & \multirow{3}{*}{$\begin{array}{l}\text { Lognormal, } \\
\text { COV }(30 \%)\end{array}$} \\
\hline & Normal, COV (10\% - 30\%) & Noureldin et al. (20) & \\
\hline & Log-normal, COV (5\% - 60\%) & Bush (35) & \\
\hline \multirow{3}{*}{$\begin{array}{l}\text { Subbase } \\
\text { modulus }\end{array}$} & Normal, COV (10\% - 30\%) & Noureldin et al. (20) & \multirow{3}{*}{$\begin{array}{l}\text { Lognormal, } \\
\text { COV }(35 \%)\end{array}$} \\
\hline & Log-normal, COV (5\% - 60\%) & Timm et al. (25) & \\
\hline & Log-normal, COV (15\% - 50\%) & Timm et al. $(21)$ & \\
\hline \multirow{2}{*}{ Traffic } & Log-normal, COV $(30 \%-42 \%)$ & Maji \& Das (36) & Lognormal, \\
\hline & Lognormal, COV (42\%) & AASHTO (37) & $\operatorname{COV}(40 \%)$ \\
\hline
\end{tabular}

As shown in Table 4, the design inputs exhibit a wide range in reported variabilities and to some extent distribution types. For this study, coefficients of variation values (COV) which are representative and which are expected under normal conditions were used. There is no reported variability for $\mathrm{DCSE}_{\mathrm{f}}$ from literature, and a statistical analysis carried out on data showed that this variability can be modelled by a log normal distribution of $30 \% \mathrm{COV}$.

\section{LRFD PROCEDURE DEVELOPMENT}

The load and resistance factor design procedure is based on the limit state design concept and utilizes probabilistically derived partial safety factors to represent the variabilities of the design inputs. A set of partial safety factors are developed to denote the risk level implied in the respective target reliabilities, and design is carried out by comparing factored resistance to the sum of factored loads (38). A typical LRFD equation can be expressed as follows:

$$
\phi R_{n}=\sum \gamma_{i} Q_{n, i}
$$

where $\phi$ is the partial safety factor for the resistance, $\gamma_{i}$ are partial safety factors for each load effect, $R_{n}$ and $Q_{n, i}$ are the nominal or mean values of the resistance and load effects respectively. In LRFD procedures, a single set of partial safety factors are recommended for a given target reliability, which considering the various design features in practice might not be possible to attain. However, by performing the reliability calibration on sections that exhibit the range of variability expected in practice it is possible to minimize the deviations that would occur 
between the target and actual reliabilities. The performance function for the Florida cracking model according to the LRFD procedure can be expressed as follows:

$$
\phi_{D C S E} D C S E_{f} \geq \gamma_{D C S E \min } D C S E_{\text {min }}
$$

where $\phi_{D C S E}$ and $\gamma_{D C S E m i n}$ are partial safety factors for the resistance and load effects respectively. $\mathrm{DCSE}_{\min }$ is the outcome of various independent variables and its factored value can be determined through the partial safety factors of asphalt thickness $\left(\phi_{H A C}\right)$, base thickness $\left(\phi_{H B}\right)$, subbase thickness $\left(\phi_{H S B}\right)$, base modulus $\left(\phi_{E B}\right)$, subbase modulus $\left(\phi_{E S B}\right)$, and traffic $\left(\gamma_{T F}\right)$, as follows:

$$
\gamma_{D C S E \min } D C S E_{\min }=f\left(\phi_{H A C} H_{A C}, \phi_{H B} H_{B}, \phi_{H S B} H_{S B}, \phi_{E B} E_{B}, \phi_{E S B} E_{S B}, \gamma_{T F} T F\right)
$$

Based on the established design period, a LRFD procedure flowchart as shown in Figure 1 is suggested for the Florida cracking model. The Design thickness for a given target reliability is obtained by comparing the factored $\mathrm{DCSE}_{\mathrm{f}}$ with the corresponding $\mathrm{DCSE}_{\min }$ value at the end of the design period.

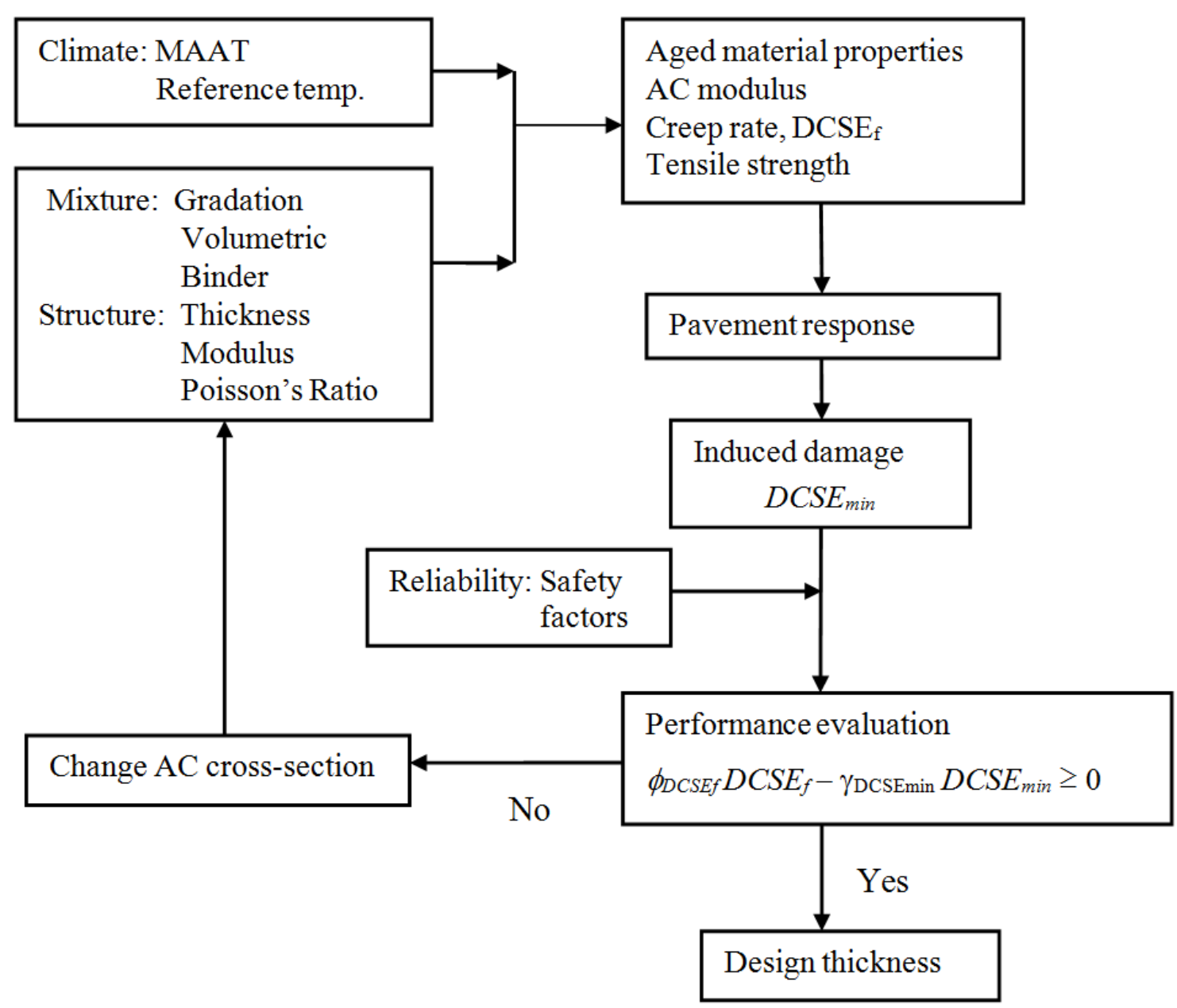

FIGURE 1 LRFD procedure flowchart for the Florida cracking model. 


\section{Partial Safety Factors}

The performance equation at the designated design period should be established as a precursor to the reliability analysis. According to the Florida cracking model, the performance equation (PE) at the end of the design period ( $\mathrm{t}=15$ years) can be expressed as follows:

$$
P E(t=15)=D C S E_{f}(t=15)-D C S E_{\text {min }}(t=15)
$$

As the response of the pavement structure is computed using a multi layered elastic model, a CCD response surface approach was employed on DCSE $_{\min }$ to generate a second degree polynomial surrogate function. It is important to evaluate the adequacy of the surrogate model before its implementation to make sure that it provides values which are in good agreement with the real model. A statistical analysis was performed on pavement section LeeSR80-2 surrogate model. As can be seen in Figure 2, there is an excellent agreement between the two models, especially considering the fact that the checking points are generated randomly using Monte Carlo simulation. Moreover, the coefficient of multiple determination $\mathrm{R}^{2}$ and adjusted $\mathrm{R}^{2}$ are 0.955 and 0.954 respectively, further validating the capacity of the surrogate model.

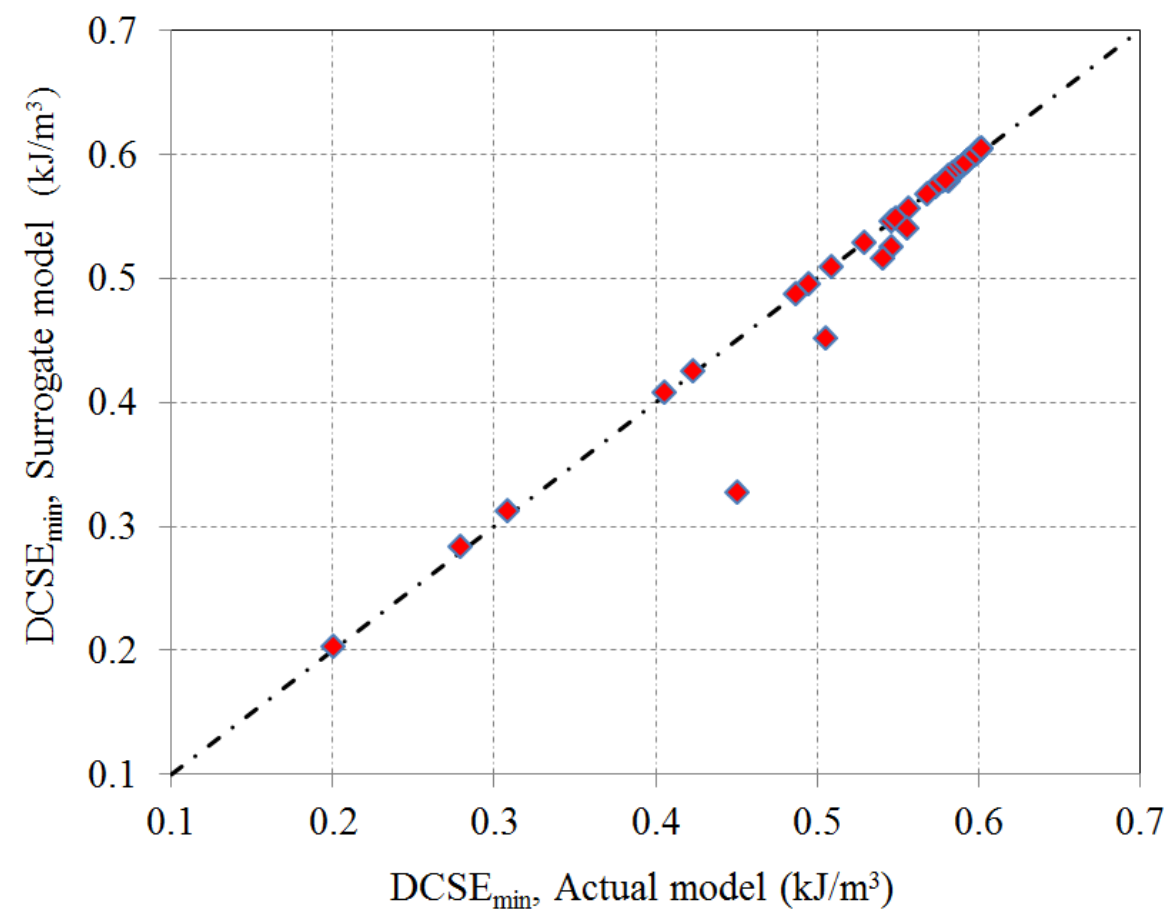

FIGURE 2 Comparisons between surrogate and actual models.

A Matlab based Rackwitz Fiessler (R-F) algorithm was used on the simplified performance function to obtain the reliability of the respective pavement sections listed in Table 1 and 2 . In addition to design reliability, analytically-based reliability techniques such as FORM provide design (failure) point and directional cosines. The direction cosines provide information regarding each design parameter contribution to the overall variance, and could be used in the formulation of partial safety factors. The following equations were used to compute the partial safety factors of each design parameter-: 


$$
\begin{aligned}
& \phi_{i}=\frac{\left(\mu_{i}^{N}+\alpha_{i} \cdot \beta_{t g t} \cdot \sigma_{i}^{N}\right)}{\mu_{i}^{N}} \\
& \gamma_{i}=\frac{\left(\mu_{i}^{N}+\alpha_{i} \cdot \beta_{t g t} \cdot \sigma_{i}^{N}\right)}{\mu_{i}^{N}}
\end{aligned}
$$

where $\mu_{i}^{N}, \sigma_{i}^{N}$ and $\alpha_{i}$ are the equivalent mean, the equivalent standard deviation and the directional cosine of the design parameters in question. The directional cosines can be used to obtain the resistance $\left(\phi_{i}\right)$ and load $\left(\gamma_{\mathrm{i}}\right)$ partial safety factors for a given target reliability $\left(\beta_{t g t}\right)$. Table 5 presents the formulated partial safety factors for the various target reliabilities. Pavement sections that have the same target reliability were pooled together to obtain a representative average partial safety factors. As can be seen in Table 5, the base and subbase thicknesses have a partial safety factor close to unity which signifies that top-down fatigue cracking is not sensitive to the variability in these parameters.

\section{TABLE 5 Partial Safety Factors}

\begin{tabular}{llllllll}
\hline $\begin{array}{l}\text { Target } \\
\text { Reliability (\%) }\end{array}$ & $\mathrm{H}_{\mathrm{AC}}$ & $\mathrm{H}_{\mathrm{B}}$ & $\mathrm{H}_{\mathrm{SB}}$ & $\mathrm{E}_{\mathrm{B}}$ & $\mathrm{E}_{\mathrm{SB}}$ & $\mathrm{TF}$ & DCSEf \\
\hline 75 & 0.979 & 0.998 & 1.000 & 0.940 & 0.986 & 1.227 & 0.905 \\
80 & 0.974 & 0.998 & 0.999 & 0.922 & 0.983 & 1.289 & 0.882 \\
85 & 0.969 & 0.998 & 0.999 & 0.908 & 0.980 & 1.348 & 0.851 \\
90 & 0.956 & 0.997 & 0.999 & 0.882 & 0.973 & 1.459 & 0.825 \\
95 & 0.947 & 0.996 & 0.999 & 0.845 & 0.963 & 1.601 & 0.775 \\
\hline
\end{tabular}

\section{Illustrative Design Examples}

Illustrative design examples were performed to evaluate the validity of the developed LRFD procedure for the Florida cracking model. For this purpose, a typical four layered pavement section (Lee SR80-2) was designed for various target reliabilities (75\% - 95\%) employing the formulated partial safety factors. The optimum design cross section was obtained by optimizing the asphalt thickness layer while keeping the rest of the parameters constant. R-F based FORM was performed on the optimized cross sections to obtain actual reliabilities.

As can be seen in Figure 3 there is an excellent agreement between the actual and target reliabilities. For all the designed sections, the deviation between the target and actual reliabilities is negligible thus giving credibility to the LRFD procedure. Moreover, the gap which is shown in the reliability group $75 \%-85 \%$ could be explained by the fact that a relatively small number of sections were used to formulate the partial safety of factors of these target reliabilities in comparison with the other group. 


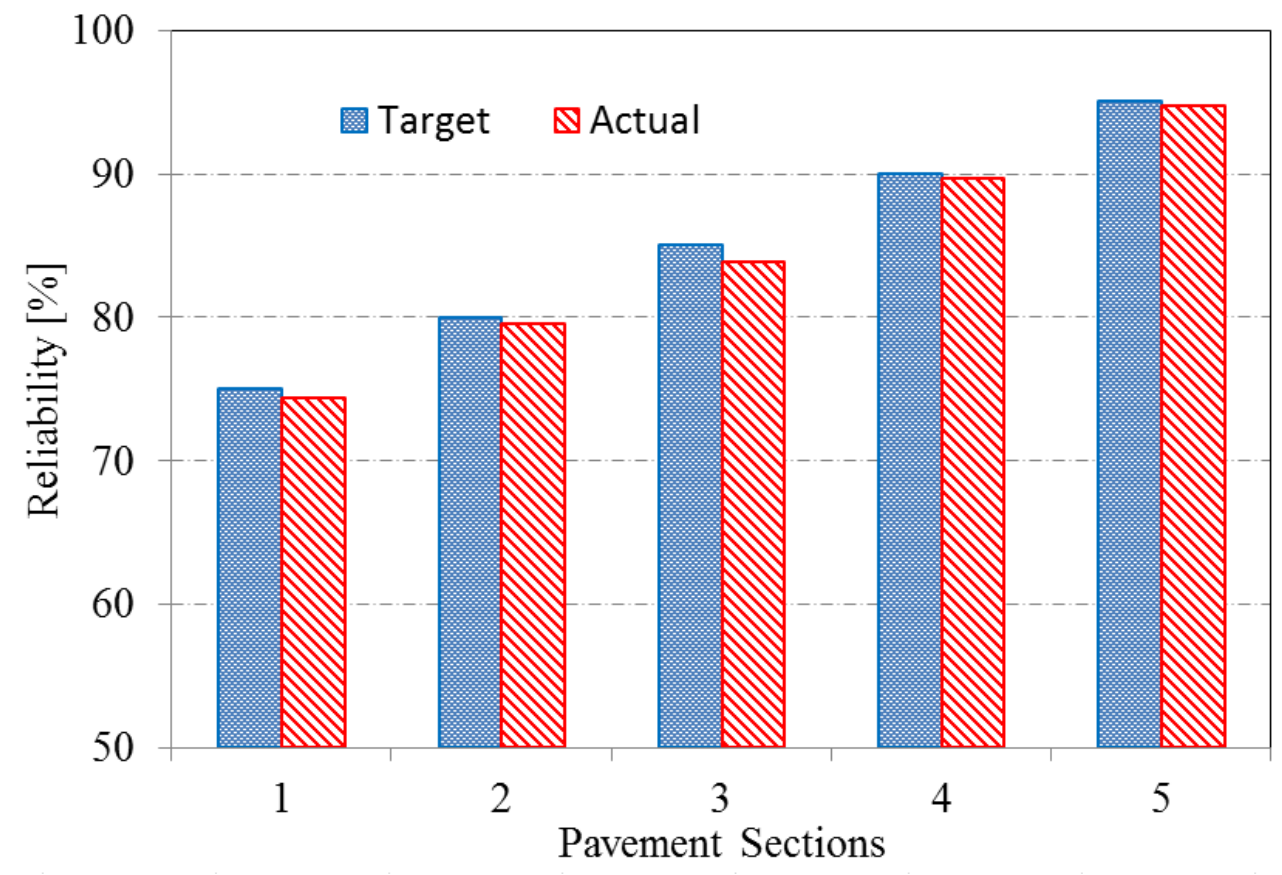

FIGURE 3 Comparisons between actual and target reliabilities.

\section{CONCLUSIONS}

The Florida cracking model incorporates an empirically derived reliability which does not consider directly the effects of design inputs variabilities on predicted performance. A reliability which is not based on probabilistic uncertainty propagation might not deliver the intended benefits as it does not provide designs of uniform reliability. The LRFD procedure which has been adopted and implemented in many structural design specifications could be developed and incorporated to pavement design procedures to provide a reliability based design.

The methodology implemented for the reliability computation and partial safety factors formulation proves to be efficient in handling the uncertainty of the design inputs and their overall effect on predicted performance. The CCD based surrogate model which was employed to represent DCSE $_{\min }$ was shown to provide an excellent approximation to the true model. Moreover, the FORM based R-F algorithm was shown to be very applicable for the evaluation of pavement reliability.

The suggested LRFD framework for the Florida cracking model was successful in delivering designs of uniform reliability while considering the inherent variability in the design inputs. The new design procedure could be used to supplement existing procedures for the design of new, existing and rehabilitated pavement sections for top-down fatigue cracking. Moreover, it could be used in quality control and quality assurance to ensure that the level of variability in design inputs is within the permissible limits.

\section{ACKNOWLEDGEMENT}

The authors would like to thank the Swedish Transportation Agency (Trafikverket) and the Swedish construction industry organization for research and development (SBUF) for providing the financial support for the project under which this work was performed. 


\section{REFERENCES}

1. Myers, L. A., and R. Roque. Top-Down Crack Propagation in Bituminous Pavements and Implications for Pavement Management. Journal of the Association of Asphalt Paving Technologists, Vol. 71, 2002.

2. Wang, L. B., L. A. Myers, L. N. Mohammad, and Y. R. Fu. Micromechanics Study on TopDown Cracking. In Transportation Research Record: Journal of the Transportation Research Board, No. 1853, Transportation Research Board of the National Academies, Washington, D.C., 2003, pp. 121-133.

3. Matsuno, S., and T. Nishizawa. Mechanism of Longitudinal Surface Cracking in Asphalt Pavements. Proc., 7th International Conference on Asphalt Pavements, Vol. 2, Nottingham, United Kingdom, 1992, pp. 277-291.

4. Uhlmeyer, J. S., K. Willoughby K, L. M. Pierce, and J. P. Mahoney. Top-Down Cracking in Washington State Asphalt Concrete Wearing Courses. In Transportation Research Record: Journal of the Transportation Research Board, No. 1730, TRB, National research Council, Washington, D.C., 2000, pp. 110-116.

5. Zhang, Z., R. Roque, B. Birgisson, and B. Sangpetgnam. Identification and Verification of a Suitable Crack Growth Law for Asphalt Mixtures. Journal of the Association of Asphalt Paving Technologists, Vol. 70, 2001, pp. 206-241.

6. Roque, R., B. Birgisson, B. Sangpetgnam, and Z. Zhang. Hot Mix Asphalt Fracture Mechanics: A Fundamental Crack Growth Law for Asphalt Mixtures. Journal of the Association of Asphalt Paving Technologists, Vol. 71, 2002, pp. 816-828.

7. Roque, R., B. Birgisson, C. Drakos, and B. Dietrich. Development and Field Evaluation of Energy-Based Criteria for Top-Down Cracking Performance of Hot Mix Asphalt. Journal of the Association of Asphalt Paving Technologists, Vol. 73, 2004, pp. 229-255.

8. Wang, J., B. Birgisson, and R. Roque. Windows-Based Top-Down Cracking Design Tool for Florida, Using Energy Ratio Concept. In Transportation Research Record: Journal of the Transportation Research Board, TRB, No. 2037,2007, pp86-96

9. Cornell, C. A. A Probability-Based Structural Code. Journal of the American Concrete Institute, Vol. 66, No. 12, 1969, pp. 974-985.

10. Rackwitz, R. Practical Probabilistic Approach to Design. Bulletin No. 112. Comite European du Beton, Paris, 1976.

11. Rackwitz, R., and B. Fiessler. Structural Reliability Under Combined Random Load Sequences. Computers and Structures, Vol. No. 5, 1978, pp. 484-494.

12. AASHTO, 1997b. Standard Specifications for Highway Bridges, American Association of State Highway and Transportation Officials, Washington, D.C., 16th Edition (1996 with 1997 Interims).

13. ACI. Building Code Requirements for Reinforced Concrete, American Concrete Institute, Detroit, 1995.

14. AISC. Load and Resistance Factor Design Specification for Structural Steel Buildings, American Institute of Steel Construction, Chicago, IL, 2nd Edition, 1994.

15. Kim, H. B., R. S. Harichandran, and N. Buch. Development of load and resistance factor design format for flexible pavements. Canadian Journal of Civil Engineering, V. 25, 1998, pp. $880-885$ 
16. Kim, H. B., and N. Buch. Reliability-based pavement design model accounting for inherent variability of design parameters. CD-ROM. Transportation Research Board, 82nd Annual Meeting, Washington DC, 2003

17. Dinegdae, Y. H., \& Birgisson, B. Reliability-based calibration for a mechanics-based fatigue cracking design procedure. Journal of Road Materials and Pavement Design.doi:10.1080/14680629.2015.1055335, 2015

18. Huang, Y. Pavement Analysis and Design, 2nd edition. Prentice Hall, Upper Saddle River, N.J., 505, 2004.

19. Darter, M. I., B. F., McCullough, and J. L. Brown. Reliability concepts applied to the Texas flexible pavement system. Highway Research Board, Record No. 407, 1972, pp. 146-161

20. Noureldin, S. A., E. Sharaf, A. Arafah, and F. Al-Sugair. Estimation of standard deviation of predicted performance of flexible pavements using AASHTO model. Transportation Research Record, No. 1449, TRB, Washington, DC, 1994, pp. 46-56,

21. Timm, D.H., B. Birgisson, and D.E. Newcomb. Variability of mechanistic-empirical flexible pavement design parameters. Proceedings of the 5th International Conference on the Bearing Capacity of Roads and Airfields, Vol. 1, 1998, Norway.

22. Lamer, A.C. and F. Moavenzadeh. Reliability of highway pavements. Highway Research Board, Record No. 362, 1971,pp. 1-8,

23. Darter, M. I., W. R. Hudson, and J.L. Brown. Statistical variation of flexible pavement properties and their consideration in design. Proceedings of the Association of Asphalt Paving Technologists, Vol. 42, 1973,pp. 589-615

24. Chua, K.H., A.D. Kiureghian, and C.L. Monismith. Stochastic model for pavement design. Journal of Transportation Engineering, ASCE, 118(6), 1992, pp. 769-785.

25. Timm, D. H., D.E. Newcomb, B. Birgisson, and T.V. Galambos. Incorporation of reliability into the Minnesota mechanistic-empirical pavement design method, Final Report Prepared to Minnesota Department of Transportation, Minnesota Univ., Department of Civil Engineering, Minneapolis, 1999

26. Retherford, J Q. and M. McDonald. Reliability Methods Applicable to MechanisticEmpirical Pavement Design Method. In Transport Research Record: Journal of the Transportation Research Board, No 2154, 2010, pp. 130-137

27. AASHTO. Guide for Design of Pavement Structures, American Association of State Highway and Transportation Officials, Washington, D.C.,1993

28. Kulkarni, R. B. Rational Approach in Applying Reliability Theory to Pavement Structural Design, In Transportation Research Record, Journal of the Transportation Research Board, No.1449, 1994, pp. 13-17

29. Hasofer, A. M. and N.C. Lind. "An exact and invariant second -moment code format." Journal of Engineering Mech. Div., ASCE, 100(1), 1974, pp. 111-121

30. Montgomery, D. C. Design and analysis of experiments: Response surface method and designs, John Wiley and Sons, New Jersey, 2005

31. Dinegdae, Y.H., I. Onifade, D. Jelagin, and B. Birgisson. Mechanics based top down fatigue cracking initiation prediction design framework for asphalt pavements. Journal of Road Materials and Pavement Design, 2015, doi: 10.1080/14680629.2015.1055335

32. Zou, Y. Development and Evaluation of an HMA Fracture Mechanics Based Model to Predict Top-Down Cracking in HMA Layers. PhD Dissertation, University of Florida, FL, 2009 
33. Florida department of transportation (FDOT). Flexible pavement condition survey handbook. Tallahassee FL, 2009

34. Florida Department of Transportation (FDOT). Roadway designs/pavement managements/reports. Retrieved from www.dot.state.fl.us, 2013

35. Bush, D. Incorporation of reliability into mechanistic-empirical pavement design in Washington and California http://courses.washington.edu/kckapur/526/526projects/Dbush. $p d f, 2004$

36. Maji, A., and A. Das. Reliability Considerations of bituminous pavement design by mechanistic-empirical approach, International Journal of Pavement Engineering, Vol. 9, No. 1, 2008, pp. 19-31

37. AASHTO. Proposed American Association of State Highway and Transportation Officials Guide for design of pavement structures, NCHRP Project 20-7/24, Vol, 2, , Washington, D.C., 1985

38. AASHTO, 1997a. LRFD Highway Bridge Design Specifications, SI Units, American Association of State Highway and Transportation Officials, Washington, D.C., First Edition (1994 with 1996 and 1997 Interims) 
